\title{
Photodynamic Therapy Using Novel Zinc Phthalocyanine Derivatives and a Diode Laser for Superficial Tumors in Experimental Animals
}

\author{
Tohru Obata ${ }^{*}$, Satoru Mori², Yuka Suzuki ${ }^{1,2}$, Takuto Kashiwagi', Etsuko Tokunaga², \\ Norio Shibata ${ }^{2}$, Motohiro Tanaka1 \\ ${ }^{1}$ Department of Bioorganic Chemistry, Faculty of Pharmaceutical Sciences, Aichi-Gakuin University, \\ Nagoya, Japan \\ ${ }^{2}$ Department of Frontier Materials, Graduate School of Engineering, Nagoya Institute of Technology, \\ Nagoya, Japan \\ Email: ${ }^{*}$ tobata@dpc.agu.ac.jp
}

Received 16 December 2014; accepted 30 December 2014; published 14 January 2015

Copyright (C) 2015 by authors and Scientific Research Publishing Inc.

This work is licensed under the Creative Commons Attribution International License (CC BY). http://creativecommons.org/licenses/by/4.0/

(c) (i) Open Access

\section{Abstract}

Photodynamictherapy (PDT) using a photo sensitizing agent and several light sources has been shown to have nonspecific and noninvasive effects on superficial cancers. Phthalocyanine (Pc) derivatives as novel photosensitizers, trifluoroethoxy-coatedzinc Pcconjugated with $\beta$-cyclodextrin $(\beta C D-4 T F E O-P c)$ was synthesized and its photodynamic effect in vitro and in vivo was evaluated. $\beta C D-4 T F E O-P c$ alone was completely non-cytotoxic even at high concentrations, and showed excellentphotodynamic effects in B16-F10 and HT-1080 cellines. The in vivo antitumor effect of $\beta C D-4 T F E O-P c$ against B16-F10 cells transplanted on to the chorioallantoic membranes of chickembryos was $52.7 \%$, but that of laserirradiation alone and photosensitizer alone was $<7 \%$ at thedose of $50 \mu \mathrm{g}$ pereggand $100 \mathrm{~J} / \mathrm{cm}^{2}(50 \mathrm{~mW})$. These data suggest that $\beta C D-4 T F E O-P c$ is a useful photosensitizer for the treatment of superficial cancers. If a high-power LED with optimal wavelength is developed, excellent treatment of superficial cancers could be achieved by applying $\beta C D$ 4TFEO-Pc for PDT.

\section{Keywords}

Photodynamic Therapy, Zinc Phthalocyanine, Photosensitizer

\footnotetext{
${ }^{*}$ Corresponding author.
}

How to cite this paper: Obata, T., Mori, S., Suzuki, Y., Kashiwagi, T., Tokunaga, E., Shibata, N. and Tanaka, M. (2015) Photodynamic Therapy Using Novel Zinc Phthalocyanine Derivatives and a Diode Laser for Superficial Tumors in Experimental Animals. Journal of Cancer Therapy, 6, 53-61. http://dx.doi.org/10.4236/jct.2015.61008 


\section{Introduction}

In recent years, photodynamic therapy (PDT) using a photosensitizing agent and several light sources has been shown to have nonspecific effects upon malignant diseases. Considerable antitumor effects of PDT have been demonstrated in patients with superficial cancers such as central-type early-stage lung cancer, early-stage gastric cancer, skin cancer, mucosal intraepithelial neoplasia, melanoma, and prostate cancer [1]-[4].

An important advantage of PDT in cancer treatment is that the photosensitizer and light are inert, and that localization of the photodynamic effect is extremely specific. To ensure that PDT is effective against deep tumors, several investigations are being conducted: development of new photosensitizers, application of light sources with deep penetration into tissues, and control of skin irritation as a diverse effect of PDT with photosensitizers [5]-[7].

Recently, several photosensitizers such as porfimer, talaporfin, temoporfin, and verteporfin have been approved for PDT in many countries [3] [8]-[10]. Porfimer, talaporfin, and temoporfin are used for superficial cancers and verteporfinfor age-related macular regeneration. These photosensitizers are derivatives of porphyrin or chlorin, and need a specific light source using red light at a wavelength of around $650 \mathrm{~nm}$.

Phthalocyanine $(\mathrm{Pc})$ derivatives are being studied intensively as second-generation photosensitizers for PDT owing to their intense absorption in the red visible region, high efficacy in producing singlet oxygen, and ease of chemical modification and formation [11]-[13]. Using Pc derivatives as photosensitizers means that their lipophilic, hydrophilic, and self-aggregation properties can be modulated by modification of the substituents on the periphery of the Pc core.

As part of our research on the development of novel functionalized Pc derivatives and syntheses of fluorine-containing compounds [14]-[16], we synthesized trifluoroethoxy-coated zinc Pc conjugated with $\beta$-cyclodextrin ( $\beta$ CD-4TFEO-Pc). We determined photodynamic effects using a diode laser of wavelength $664 \mathrm{~nm}$. In the present study, we ascertained if newly developed zinc Pc derivatives as photosensitizers have photodynamic effects in vitro and in vivo.

\section{Materials and Methods}

\subsection{Tumor Cells}

Murine melanoma (B16-F10) and human fibrosarcoma (HT-1080) cells were obtained from JCRB Cell Bank, Japanese Collection of Research Bioresources (Osaka, Japan). The cells were maintained in RPMI-1640 medium supplemented with $10 \%$ fetal bovine serum and antibiotics, and were harvested by trypsinization before use.

\subsection{Photosensitizer}

All test compounds are shown in Figure 1. Pc coated with a trifluoroethoxy functional group and conjugated with cyclodextrin (CD) contained zinc as a central chelating metal. According to Das et al., perfluoro zinc Pc was synthesized. The CD conjugation to zinc Pc were synthesized by our research team [17]. Synthetic methods and chemical properties will be reported elsewhere. Talaporfinwas kindly provided by the Pharmaceutical Research Center of Meiji Seika Pharma (Kanagawa, Japan).

\subsection{Laser Equipment}

A diode laser (kindly provided by Panasonic, Osaka, Japan) was employed to obtain a wavelength of $664 \mathrm{~nm}$ (which enables deep penetration into tissues). The laser beam was delivered via quartz fibers. Laser light was irradiated vertically onto tumor cells and tissues. Previously, we had confirmed that this condition for laser irradiation did not affect tumor cells in vitro. The power of basically irradiated laser was adapted at $100 \mathrm{~J} / \mathrm{cm}^{2}(150$ $\mathrm{mW})$, but some irradiated laser power was controlled by irradiated time.

\subsection{In Vitro Chemosensitivity of Photosensitizers with Laser Irradiation}

Aliquots $(495 \mu \mathrm{L})$ of a cell suspension $(2000$ cells/mL) in exponential growth were seeded into 48 microwell plates and preincubated for $24 \mathrm{~h}$ at $37^{\circ} \mathrm{C}$. Five microliters of various concentrations of photosensitizers in dimethyl sulfoxide (DMSO) was added to each well and incubated for $5 \mathrm{~h}$. After washing out test photosensitizers 


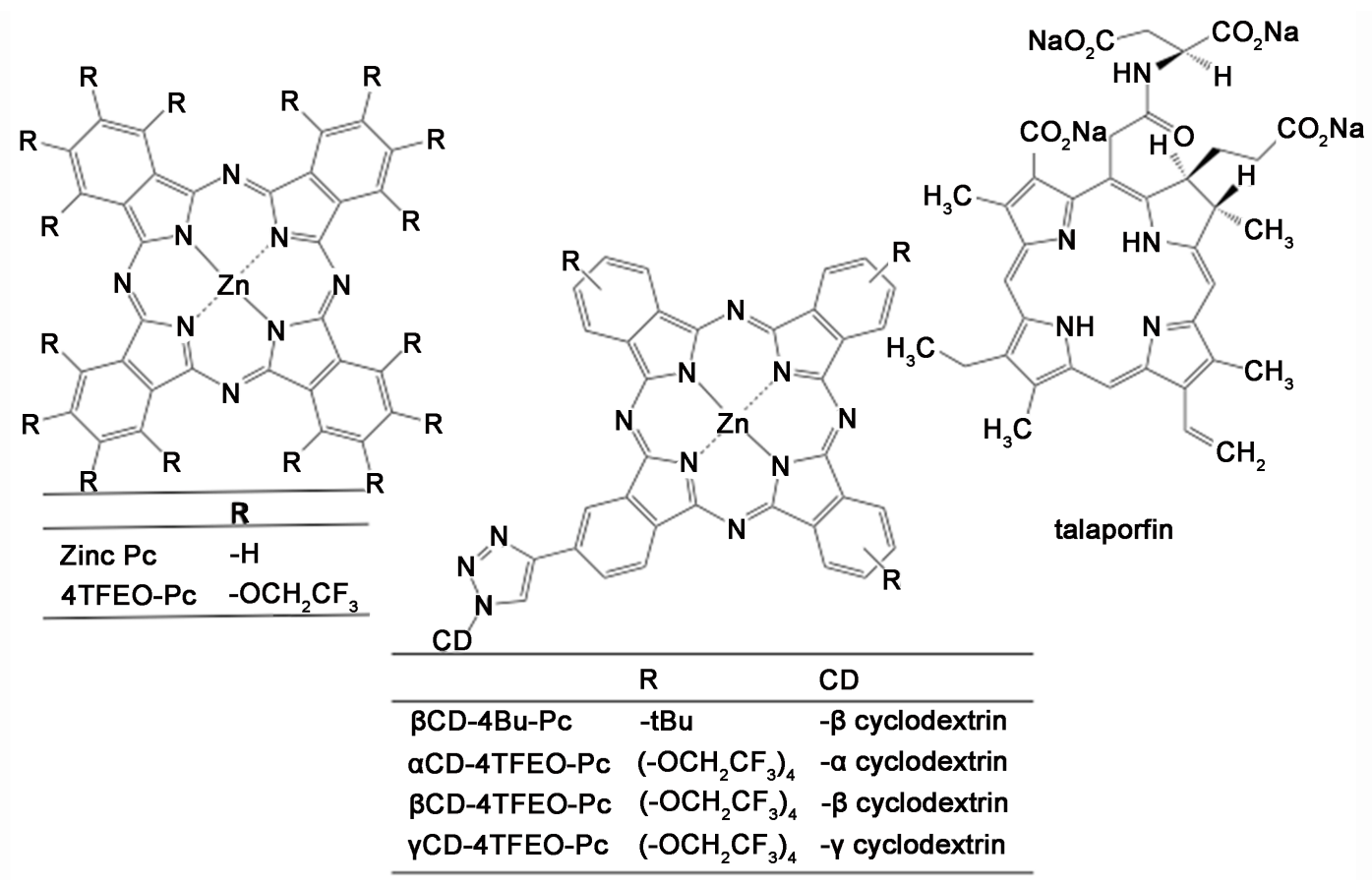

Figure 1. Structures of phthalocyanine derivatives.

with fresh medium twice, $500 \mu \mathrm{L}$ of fresh medium was added to each well and laser irradiation was undertaken vertically at $100 \mathrm{~J} / \mathrm{cm}^{2}(150 \mathrm{~mW})$. The plate was incubated for $24 \mathrm{~h}$, and the inhibitory effects of photosensitizers on the growth of tumor cells were examined using a colorimetric assay, 3-(4,5-dimethylthiazol-2-yl)-2,5diphenyltetrazolium bromide (MTT). Briefly, $30 \mu \mathrm{L}$ of MTT solution (3 mg/mL in phosphate-buffered saline) was added to each well, and cell cultures were incubated further for $4 \mathrm{~h}$ at $37^{\circ} \mathrm{C}$. After removal of the medium, resultant MTT formazan crystals were dissolved in $400 \mu \mathrm{L}$ of DMSO. The absorbance of each well was measured at $570 \mathrm{~nm}$ by using a microplate reader (MTP-800AFC; Corona Electric, Hitachinaka, Japan), and the inhibition ratio (IR) was calculated using the following formula:

$$
\operatorname{IR}(\%)=(1-T / C) \times 100
$$

where $C$ is the mean value of the optical densities of the control group and $T$ is that of the treatment group. Halfmaximal inhibitory concentration $\left(\mathrm{IC}_{50}\right)$ was defined as the concentration of photosensitizers required to induce a $50 \%$ reduction in growth relative to that in the control. The $\mathrm{IC}_{50}$ value was determined by graphical correlation of the dose-response curve with at least 3 photosensitizer concentrations.

\subsection{In Vivo Evaluation of PDT Using a Chick Embryo Assay}

According to our former study [18]-[21], in vivo antitumor effects can be evaluated and correlated using a chick embryo assay. Fertilized chicken eggs (Goto Farms, Gifu, Japan) were incubated in a forced-draft incubator maintained at $37^{\circ} \mathrm{C}$ and $70 \%$ humidity. On day 10 , eggs were candled and Y-shaped blood-vessel junctions on the chorioallantoic membrane (CAM) were marked on the shell with a pencil. Then, about 10-mm square "window" was made through the mark. The CAM was depressed by applying gentle suction at the air sac, and the shell membrane was stripped off carefully to expose the CAM. A sterilized Teflon ${ }^{\circledR}$ ring (diameter, $8 \mathrm{~mm}$ ) was put on the junction of the blood vessels, and $10 \mu \mathrm{L}$ of B16-F10 cell suspension $\left(2.0 \times 10^{7}\right.$ cells $\left./ \mathrm{mL}\right)$ was pipetted through the ring into the opening. The window in the shell was sealed with OpSite ${ }^{\circledR}$ (Smith \& Nephew, London, UK) and the treated egg was incubated again.

On day 11, the Teflon ${ }^{\circledR}$ ring was removed from the CAM surface and the eggs were incubated for $24 \mathrm{~h}$. Test photosensitizers were injected into the CAM vein with a 30-G needle on day 12 . Briefly, a portion of shell directly overlying a blood vessel was removed carefully. The vein was made visible with a drop of paraffin oil applied to the shell membrane. Test photosensitizers ( $50 \mu \mathrm{g} / \mathrm{host}$ ) were injected into the CAM vein with $0.2 \mathrm{~mL}$ of 
physiological $(0.9 \%) \mathrm{NaCl}$ solution. Then, the photosensitizer-injected window was sealed with Tegaderm ${ }^{\circledR}$ (Sumitomo 3M, Tokyo, Japan). Thirty minutes after photosensitizer administration, the diode laser was used for vertical irradiation of the tumor at $100 \mathrm{~J} / \mathrm{cm}^{2}(150 \mathrm{~mW})$ through the opened window. The eggs were incubated for 5 more days.

On day 17, the tumor that had grown on the CAM was excised from the CAM, dissected free of adhesive chick tissue, and weighed. The IR for the tumor was calculated using the following formula:

$$
\operatorname{IR}(\%)=(1-B / A) \times 100
$$

where $A$ is the mean tumor weight of the control group and $B$ is that of the treatment group. The effectiveness of each photosensitizer was analyzed using the Student's $t$-test. The in vivo antitumor experiment was approved (13-023) by the ethics committee of Aichi Gakuin University.

\subsection{Statistical Analysis}

All in vitro data are expressed as means in several independent experiments. The data of in vivo are expressed as means \pm SD and significance are performed using Student's $t$-test. $P$-values $<0.001$ were considered statically significant.

\section{Results}

\subsection{In Vitro Antitumor Effect Using PDT against B16-F10 and HT-1080 Cells}

The in vitro antitumor effects of Pc derivatives are shown in Figure 2. In B16-F10 cells, zinc Pc exhibited the same cytotoxicity with or without laser irradiation. However, HT-1080 cells treated with zinc Pc were sensitive to laser irradiation. $\beta$ CD-4TFEO-Pc alone was completely non-cytotoxic even at a high concentration and showed an excellent photodynamic effect in both cell lines. These results suggested that $\beta$ CD-4TFEO-Pc had a wide margin of safety, and that the toxicity against normal cells and non-irradiated cells was quite low. Talaporfin demonstrated a good photodynamic effect, but high IRs were noted in photosensitizers alone and the PDT group at high concentrations. IC 50 values of various compounds that were subjected to/were not subjected laser irradiation are summarized in Table 1 . All test photosensitizers had higher $\mathrm{IC}_{50}$ values than that of photosensitizers that underwent laser irradiation, but large differences among these photosensitizers were noted. The $\mathrm{IC}_{50}$ value of any modified compound alone was increased by $>70$-fold than that of the mother compound (zinc Pc). However, the photodynamic effect of all derivatives was greater than that of zinc Pc in B16-F10 cells (though high sensitivity of laser irradiation with zinc Pc was noted in HT-1080 cells). In particular, derivatives with both $\mathrm{CD}$ and trifluoroethoxy functional groups exhibited excellent photodynamic effects. $\beta$ CD-4TFEO-Pc had a greater difference in $\mathrm{IC}_{50}$ value than the other derivatives, and the greatest photodynamic effect (156-fold) was

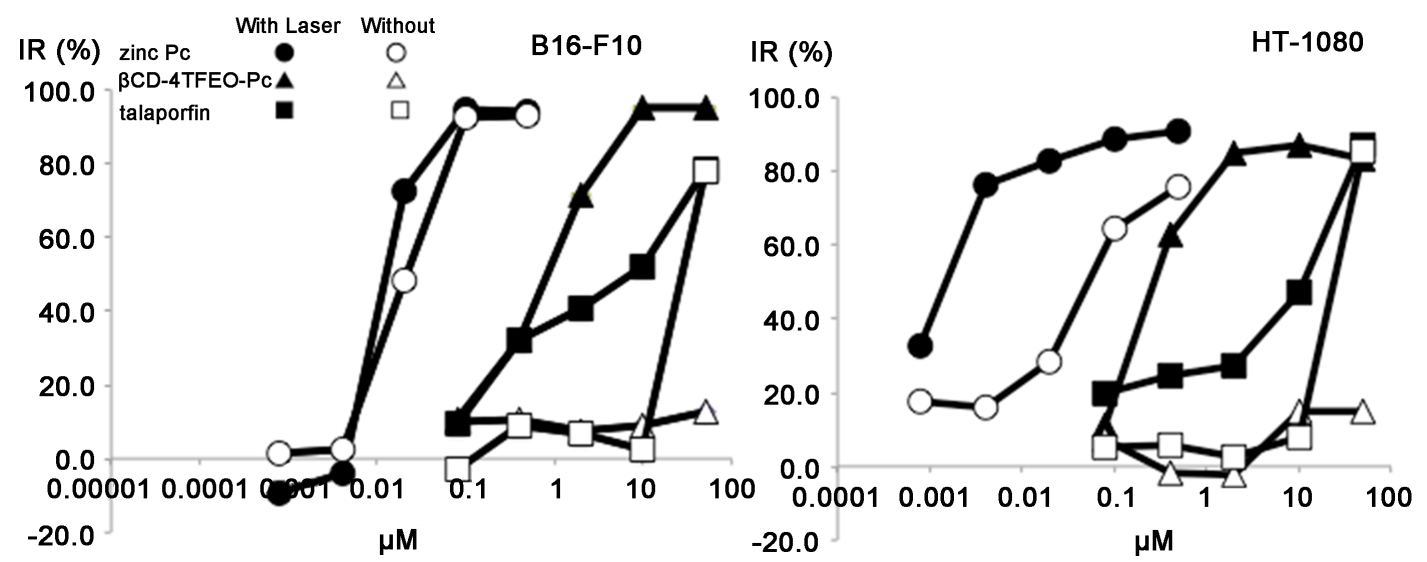

Figure 2. Growth inhibitory effect of PDT on B16-F10 melanoma and HT-1080 cells in vitro. Cells were treated with zinc Pc $(\bullet), \beta$ CD-4TFEO-Pc $(\boldsymbol{\Delta})$ and talaporfin $(\boldsymbol{\bullet})$ at $37^{\circ} \mathrm{C}$ for $24 \mathrm{~h}$ and irradiated with (closed) or without (opened) the laser. Cell viability was determined by the MTT assay $24 \mathrm{~h}$ after laser irradiation. The cytotoxicity of the laser alone was $<10 \%$. 
Table 1. Comparison of $\mathrm{IC}_{50}$ values with laser PDT among phthalocyanine derivatives.

\begin{tabular}{|c|c|c|c|c|c|c|}
\hline & \multicolumn{6}{|c|}{$\mathrm{IC}_{50}(\mu \mathrm{M})$} \\
\hline & \multicolumn{3}{|c|}{ B16-F10 } & \multicolumn{3}{|c|}{ HT-1080 } \\
\hline & Drug only & $\mathrm{PDT}^{\mathrm{a}}$ & Effective ratio $^{\mathrm{b}}$ & Drug only & $\mathrm{PDT}^{\mathrm{a}}$ & Effective ratio ${ }^{\mathrm{b}}$ \\
\hline Zinc Pc & 0.023 & 0.015 & 1.5 & 0.068 & 0.0021 & 32.4 \\
\hline 4TFEO-Pc & $\geq 50$ & 31.8 & $\geq 1.6$ & 27.5 & 5.52 & 5.0 \\
\hline$\beta \mathrm{CD}-\mathrm{tBu}-\mathrm{Pc}$ & 16.7 & 1.10 & 15.2 & 5.31 & 0.58 & 9.2 \\
\hline$\alpha \mathrm{CD}-4 \mathrm{TFEO}-\mathrm{Pc}$ & $\geq 50$ & 1.29 & $\geq 38.8$ & $\geq 50$ & 1.32 & $\geq 37.9$ \\
\hline$\beta$ CD-4TFEO-Pc & $\geq 50$ & 1.12 & $\geq 44.6$ & $\geq 50$ & 0.32 & $\geq 156$ \\
\hline$\gamma$ CD-4TFEO-Pc & $\geq 50$ & 1.25 & $\geq 40.0$ & $\geq 50$ & 1.67 & $\geq 29.9$ \\
\hline Talaporfin & 35.1 & 8.50 & 4.1 & 31.7 & 12.8 & 2.5 \\
\hline
\end{tabular}

${ }^{a}$ PDT comprised laser irradiation. ${ }^{b}$ Effective ratio shows ratio $v s$. drug only.

found in HT-1080 cells. In contrast, there was a slight difference in talaporfin IC $_{50}$ value between the PDT group and talaporfin only group.

\subsection{Optimization of the Dose of Laser Irradiation}

The sensitivity of $\beta$ CD-4TFEO-Pc with various doses of laser irradiation $\left(0-200 \mathrm{~J} / \mathrm{cm}^{2}\right)$ to B16-F10 cells is shown in Figure 3. A high concentration of $\beta$ CD-4TFEO-Pc alone resulted in slight cytotoxicity (22\%). Laser irradiation alone (without $\beta$ CD-4TFEO-Pc) resulted in virtually no cytotoxicity. In cells treated with a combination of $\beta$ CD-4TFEO-Pc and laser irradiation, tumor growth was inhibited significantly by laser irradiation in a dose-dependent manner. This dependency of the dose of laser irradiation was also confirmed in the case of other zinc Pc derivatives and cell lines (data not shown).

\subsection{In Vivo Antitumor Activity Using Chick Embryos}

$\beta$ CD-4TFEO-Pc showed excellent antitumor activity in vitro; therefore, photosensitizers were evaluated in an in vivo antitumor assay system using fertilized chicken eggs. Tumor cells of various species can be inoculated on the CAM because chicken eggs are naturally immunodeficient before hatching, and good proliferation of tumor cells has been observed in several studies [18]-[21]. Several investigations using the chick embryo assay to evaluate antitumor activity in vivo have been carried out. This assay method is rapid, convenient, inexpensive, and causes less pain to experimental animals. The antitumor effects of $\beta$ CD-4TFEO-Pc against B16-F10 cells transplanted onto the CAM of a chick embryo are shown in Figure 4. The tumor IR of $\beta$ CD-4TFEO-Pc with laser irradiation was $52.7 \%(\mathrm{p}<0.001)$, and that of laser irradiation alone and photosensitizer alone was $<7 \%$ at $50 \mu \mathrm{g}$ per egg and at $100 \mathrm{~J} / \mathrm{cm}^{2}(150 \mathrm{~mW})$.

\section{Discussion}

Zinc Pc derivatives are expected to be second-generation photosensitizers because they have relatively high absorbance at red light, which can reach deep into tissues. However, they show $\pi-\pi$ stacking, which results in aggregation in water, and they also have low solubility [11] [12]. To overcome these drawbacks, we synthesized novel zinc Pc derivatives containing fluorine [14] [16] [17] and also conjugate CD molecules.

In novel zinc Pc derivatives, $\beta$ CD-4TFEO-Pc exhibited greater photodynamic effects than those seen with talaporfin, which is used widely for the treatment of early-stage lung cancer and malignant primary brain tumors. Our study showed that $\beta$ CD-4TFEO-Pc was non-toxic and that laser irradiation was needed for $\beta$ CD-4TFEO-Pc to exhibit its antitumor activity because it can produce singlet oxygen as an active species to abrogate tumor proliferation. Though the wavelength used $(664 \mathrm{~nm})$ was not optimal against $\beta$ CD-4TFEO-Pc, it showed great sensitivity to laser irradiation. The equipment to create laser light was developed for the PDT of talaporfin in clinical scenarios; therefore, the wavelength of irradiation matched exactly to the intense absorption of talaporfin 


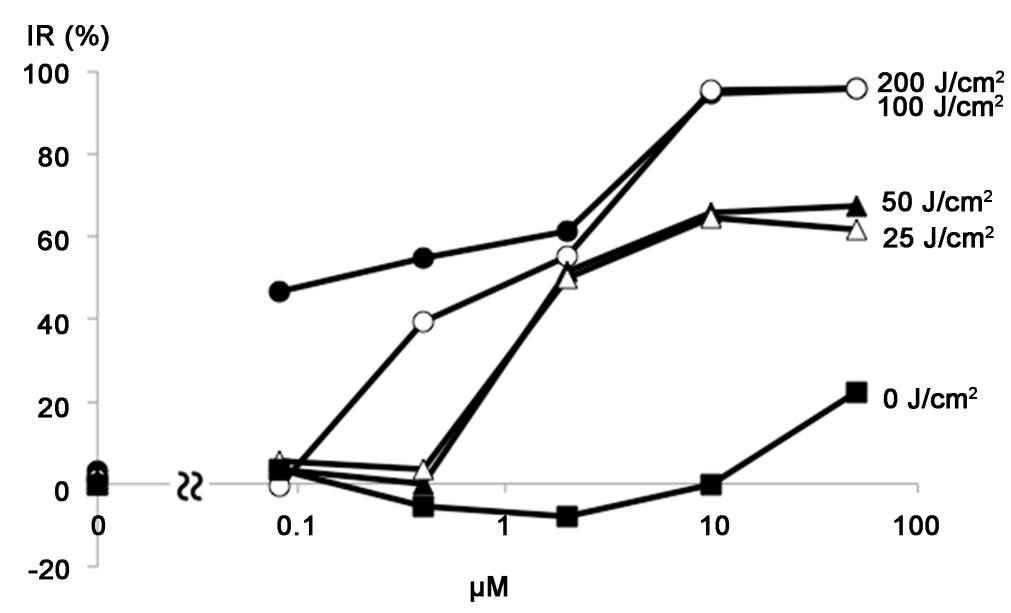

Figure 3. Correlation of laser energy and cytotoxicity of B16-F10 melanomatreated $\beta$-CD-4TFEO-Pc in vitro. B16-F10 cells were treated with photosensitizer at various concentrations for $5 \mathrm{~h}$. After removing the photosensitizer, cells were irradiated with or without the laser (0 ( $)$ ), $25(\Delta), 50(\Delta), 100(0)$, $\left.200(\bullet) \mathrm{J} / \mathrm{cm}^{2}, 664 \mathrm{~nm}\right)$. Cytotoxicity was determined by the MTT assay $24 \mathrm{~h}$ after irradiation. Each point is the mean of $\geq 3$ independent experiments, and error bar represents the standard deviation.

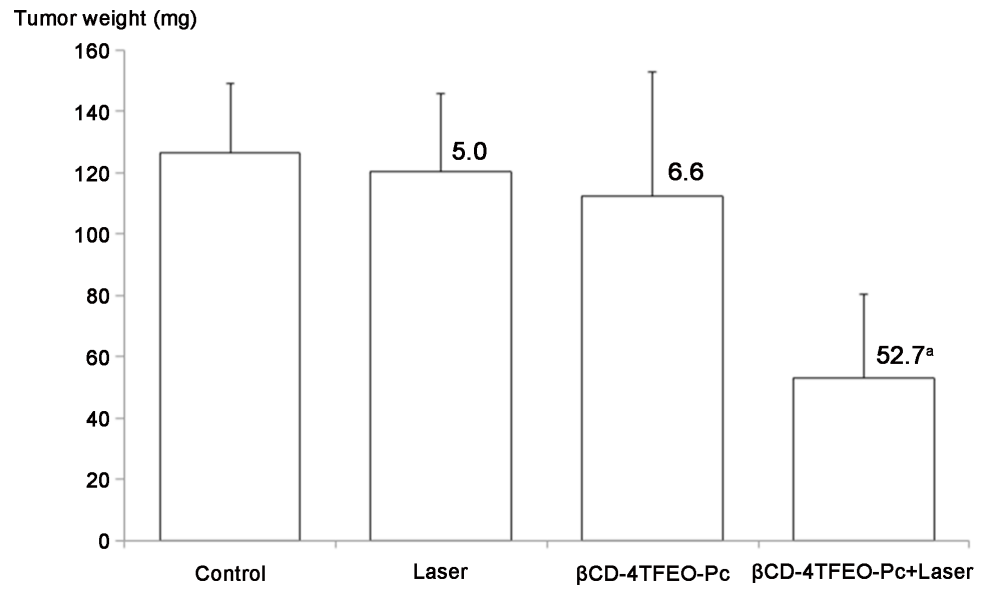

Figure 4. In vivo antitumor activity of $\beta$ CD-4TFEO-P determined using a chick embryo assay. Antitumor activity of $\beta$ CD-4TFEO-Pc with laser irradiation against the growth of B16-F10 tumor cells on CAM was evaluated on day 17. 'Significance determined by the Student's $t$-test $(p<0.001)$ is indicated. Values show the inhibition ratio (\%) vs. control tumor weight.

[22]. The intense absorption of $\beta$ CD-4TFEO-Pc was shifted to around $700 \mathrm{~nm}$ owing to modification of the Pc skeleton, and light of wavelength $664 \mathrm{~nm}$ that was irradiated was not of sufficient wavelength to exert the maximum photodynamic effect for $\beta$ CD-4TFEO-Pc. Nevertheless, the excellent antitumor activity of $\beta$ CD-4TFEOPc was demonstrated in the present study and its clinical application as a photosensitizer is expected. A photosensitizer that is sensitive to a specific light source and laser irradiation are important factors in PDT for treatment of superficial cancer. The dependency of laser irradiation is revealed in Figure 3 and it was suggested that a high-powered laser exhibited antitumor activity. High-power laser irradiation can produce heat at localized irradiated areas; thus, evaluation of antitumor activity is thought to involve photodynamic and hyperthermic effects. At $100 \mathrm{~J} / \mathrm{cm}^{2}$, laser irradiation showed effective antitumor effects without producing heat. Even low-power laser irradiation could activate photosensitizers to produce singlet oxygen as an active species to abrogate tumor proliferation. 
Conjugation of CDs to zinc Pc dramatically improved water solubility, and coating of fluorine to zinc Pc prevented self-aggregation. When several zinc Pc derivatives coated with fluorine (including 4TFEO-Pc) were examined for photodynamic effects, it appeared that introduction of fluorine led to an increase in photodynamic effects. CD conjugation resulted in an increase in hydrophilicity (which is thought to be a useful property for intestinal absorption, increases in bioavailability, and drug preparation) [23] [24]. Conventional photosensitizers exhibit non-specific cytotoxicity against non-irradiated cells; hence, patients should shade from light including sunbeam such treatment for several days to avoid side effects. Even high concentrations of $\beta$ CD-4TFEO-Pc showed very low cytotoxicity upon treatment with $\beta$ CD-4TFEO-Pc alone. Low sensitivity is a very useful property for a photosensitizer. This useful phenomenon was observed with derivatives with fluorine and CD conjugation. $\beta C D$ comprising six glucose molecules seemed to be optimal for photodynamic effects; thus, the Pc motif probably matched the pore size of $\beta \mathrm{CD}$.

The mother compound, Zinc Pc, showed higher cytotoxicity than $\beta$ CD-4TFEO-Pc and talaporfin in B16-F10 and HT-1080 cells. This activity was non-specific for laser irradiation in B16-F10 cells. Laser irradiation did not completely affect the chemosensitivity of zinc Pc. It seems that the extremely high cytotoxicity of zinc Pc masked photodynamic effects. However, in HT-1080 cells, zinc Pc showed moderate photodynamic effects with high cytotoxicity. Thus, we suspected that laser irradiation was not sufficient to penetrate B16-F10 cells (which originate from melanoma and contain large amounts of melanin pigment), because there were reported that pigmented tumors were resistance to the PDT [25] [26]. B16-F10 and HT-1080 cells treated with talaporfin and laser irradiation achieved weak photodynamic effects, but at high doses, the photodynamic effect elicited by talaporfin disappeared. The range of drug concentrations used was narrow; therefore, the plasma concentration after drug administration and area of laser irradiation should be monitored very carefully.

In this paper, the CAM assay using chicken eggs as in vivo chemosensitivity test was performed. The model of chick embryos can correctly predict a clinical response of chemotherapy in the several tumors such as lung cancer and malignant glioma and any study as in vivo model were adapted the CAM assay [19] [20] [27]. A total of $50 \mu \mathrm{g} / \mathrm{egg} \beta \mathrm{CD}-4 \mathrm{TFEO}-\mathrm{Pc}$ was administered into the CAM vein of eggs and the inhibitory effect of tumor growth was evaluated by tumor weight on day 17 from fertilization. A significant difference in the $\beta$ CD-4TFEOPc group plus laser irradiation compared with the control group was noted with regard to tumor proliferation on the CAM of eggs, but laser irradiation and $\beta$ CD-4TFEO-Pc alone did not show inhibitory effects. Moreover, in one egg with $\beta$ CD-4TFEO-Pc plus laser irradiation, the implanted tumor was quite small on day 17 . If an optimal dose and timing of $\beta$ CD-4TFEO-Pc administration and optimal wavelength of laser irradiation are applied, excellent antitumor activity (e.g., abrogation of tumor proliferation) could be achieved.

\section{Conclusion}

We suggest that $\beta$ CD-4TFEO-Pc is a useful photosensitizer for the treatment of superficial cancers. If a highpower light source [7] to match its specific wavelength can be developed, excellent treatment of superficial cancers could be achieved by applying $\beta$ CD-4TFEO-Pc for PDT.

\section{Acknowledgements}

The authors thank the Pharmaceutical Research Center of Meiji Seika Pharma and Panasonic. The in vivo antitumor experiment performed using chick embryo was approved (13-023) by the ethics committee of Aichi Gakuin University.

\section{References}

[1] Anand, S., Ortel, B.J., Pereira, S.P., Hasan, T. and Maytin, E.V. (2012) Biomodulatory Approaches to Photodynamic Therapy for Solid Tumors. Cancer Letters, 326, 8-16. http://dx.doi.org/10.1016/j.canlet.2012.07.026

[2] Baldea, I. and Filip, A.G. (2012) Photodynamic Therapy in Melanoma-An Update. Journal of Physiology and Pharmacology, 63, 109-118. http://www.jpp.krakow.pl/journal/archive/04 12/pdf/109 0412 article.pdf

[3] Ikeda, N., Usuda, J., Kato, H., Ishizumi, T., Ichinose, S., Otani, K., Honda, H., Furukawa, K., Okunaka, T. and Tsutsui, H. (2011) New Aspects of Photodynamic Therapy for Central Type Early Stage Lung Cancer. Lasers in Surgery and Medicine, 43, 749-754. http://dx.doi.org/10.1002/lsm.21091

[4] Mimura, S., Narahara, H., Otani, T. and Okuda, S. (1999) Progress of Photodynamic Therapy in Gastric Cancer. Di- 
agnostic and Therapeutic Endoscopy, 5, 175-182. http://dx.doi.org/10.1155/dte.5.175

[5] Tanaka, M., Kinoshita, M., Yoshihara, Y., Shinomiya, N., Seki, S., Nemoto, K., Hirayama, T., Dai, T., Huang, L., Hamblin, M.R. and Morimoto, Y. (2012) Optimal Photosensitizers for Photodynamic Therapy of Infections Should Kill Bacteria but Spare Neutrophils. Photochemistry and Photobiology, 88, 227-232. http://dx.doi.org/10.1111/j.1751-1097.2011.01005.x

[6] Allison, R. R. and Moghissi, K. (2013) Photodynamic Therapy (pdt): Pdt Mechanisms. Clinical Endoscopy, 46, 24-29. http://dx.doi.org/10.5946/ce.2013.46.1.24

[7] Saini, R. and Poh, C.F. (2013) Photodynamic Therapy: A Review and Its Prospective Role in the Management of Oral Potentially Malignant Disorders. Oral Diseases, 19, 440-451.http://dx.doi.org/10.1111/odi.12003

[8] Opitz, I., Krueger, T., Pan, Y., Altermatt, H.J., Wagnieres, G. and Ris, H.B. (2006) Preclinical Comparison of Mthpc and Verteporfin for Intracavitary Photodynamic Therapy of Malignant Pleural Mesothelioma. European Surgical Research, 38, 333-339. http://dx.doi.org/10.1159/000094028

[9] Huggett, M.T., Jermyn, M., Gillams, A., Illing, R., Mosse, S., Novelli, M., Kent, E., Bown, S.G., Hasan, T., Pogue, B.W. and Pereira, S.P. (2014) Phase i/ii Study of Verteporfin Photodynamic Therapy in Locally Advanced Pancreatic Cancer. British Journal of Cancer, 110, 1698-1704. http://dx.doi.org/10.1038/bjc.2014.95

[10] Tanaka, M., Uchibayashi, T., Obata, T. and Sasaki, T. (1995) Photodynamic Therapy of Photofrin ii and Excimer Dye Laser on Experimental Tumors. Cancer Letters, 90, 163-169. http://dx.doi.org/10.1016/0304-3835(95)03699-W

[11] Magaraggia, M., Marigo, L., Pagnan, A., Jori, G. and Visona, A. (2007) Porphyrin-Photosensitized Processes: Their Applications in the Prevention of Arterial Restenosis. Cardiovascular \& Hematological Agents in Medicinal Chemistry, 5, 278-288. http://dx.doi.org/10.2174/187152507782109908

[12] Van Lier, J.E. and Spikes, J.D. (1989) The Chemistry, Photophysics and Photosensitizing Properties of Phthalocyanines. Ciba Foundation Symposium, 146, 17-26.

[13] Gorman, S.A., Brown, S.B. and Griffiths, J. (2006) An Overview of Synthetic Approaches to Porphyrin, Phthalocyanine, and Phenothiazine Photosensitizers for Photodynamic Therapy. Journal of Environmental Pathology, Toxicology and Oncology, 25, 79-108. http://dx.doi.org/10.1615/JEnvironPatholToxicolOncol.v25.i1-2.50

[14] Yoshiyama, H., Shibata, N., Sato, T., Nakamura, S. and Toru, T. (2008) Synthesis and Properties of TrifluoroethoxyCoated Binuclear Phthalocyanine. Chemical Communications, 7, 1977-1979. http://dx.doi.org/10.1039/b800918j

[15] Reddy, M.R., Shibata, N., Kondo, Y., Nakamura, S. and Toru, T. (2006) Design, Synthesis, and Spectroscopic Investigation of Zinc Dodecakis(trifluoroethoxy)phthalocyanines Conjugated with Deoxyribonucleosides. Angewandte Chemie International Edition, 45, 8163-8166. http://dx.doi.org/10.1002/anie.200603590

[16] Yoshiyama, H., Shibata, N., Sato, T., Nakamura, S. and Toru, T. (2009) Synthesis of Trifluoroethoxy-Coated Binuclear Phthalocyanines with Click Spacers and Investigation of Their Clamshell Behaviour. Organic \& Biomolecular Chemistry, 7, 2265-2269. http://dx.doi.org/10.1039/b902905b

[17] Das, B., Tokunaga, E., Tanaka, M., Sasaki, T. and Shibata, N. (2010) Perfluoroisopropyl Zinc Phthalocyanines Conjugated with Deoxyribonucleosides: Synthesis, Photophysical Properties and in Vitro Photodynamic Activities. European Journal of Organic Chemistry, 2010, 2878-2884. http://dx.doi.org/10.1002/ejoc.201000179

[18] Uchida, H., Sasaki, T., Tanaka, M., Endo, Y., Nitta, K., Nishikawa, K., Chuman, H., Fukuma, H. and Matsumoto, K. (1987) Response to Antitumor Agents of Murine Transplantable Tumors Implanted onto Chorioallantoic Membrane of Chick Embryo. Japanese Journal of Cancer Research, 78, 729-736.

[19] Nishikawa, K., Sasaki, T., Tanaka, M., Uchida, H., Endo, Y., Fukuma, H., Chuman, H., Beppu, Y., Matsumoto, K. and Nitta, K. (1987) Experimental Model for Predicting Metastatic Ability of Tumors Using Chick Embryo. Japanese Journal of Clinical Oncology, 17, 319-325.

[20] Shoin, K., Yamashita, J., Enkaku, F., Sasaki, T., Tanaka, M. and Endo, Y. (1991) Chick Embryo Assay as Chemosensitivity Test for Malignant Glioma. Cancer Science, 82, 1165-1170. http://dx.doi.org/10.1111/j.1349-7006.1991.tb01772.x

[21] Tanaka, M., Matsuda, A., Terao, T. and Sasaki, T. (1992) Antitumor Activity of a Novel Nucleoside, 2'-C-cyano-2'deoxy-1- $\beta$-D-arabinofuranosylcytosine (CNDAC) against Murine and Human Tumors. Cancer Letters, 64, 67-74. http://dx.doi.org/10.1016/0304-3835(92)90024-P

[22] Yoshida, T., Tokashiki, R., Ito, H., Shimizu, A., Nakamura, K., Hiramatsu, H., Tsukahara, K., Shimizu, S., Takata, D., Okamoto, I. and Suzuki, M. (2008) Therapeutic Effects of a New Photosensitizer for Photodynamic Therapy of Early Head and Neck Cancer in Relation to Tissue Concentration. Auris Nasus Larynx, 35, 545-551. http://dx.doi.org/10.1016/j.anl.2007.10.008

[23] Loftsson, T. and Masson, M. (2001) Cyclodextrins in Topical Drug Formulations: Theory and Practice. International Journal of Pharmaceutics, 225, 15-30. http://dx.doi.org/10.1016/S0378-5173(01)00761-X

[24] Carrier, R.L., Miller, L.A. and Ahmed, I. (2007) The Utility of Cyclodextrins for Enhancing Oral Bioavailability. 
Journal of Controlled Release, 123, 78-99. http://dx.doi.org/10.1016/j.jconrel.2007.07.018

[25] Sharma, K.V., Bowers, N. and Davids, L.M. (2011) Photodynamic Therapy-Induced Killing Is Enhanced in Depigmented Metastatic Melanoma Cells. Cell Biology International, 35, 939-944. http://dx.doi.org/10.1042/CBI20110103

[26] Calzavara-Pinton, P.G. (1995) Repetitive Photodynamic Therapy with Topical Delta-Aminolevulinic Acid as an Appropriate Approach to the Routine Treatment of Superficial Non-Melanoma Skin Tumours. Journal of Photochemistry and Photobiology B, 29, 53-57. http://dx.doi.org/10.1016/1011-1344(95)90253-8

[27] Tanaka, M., Tatsuzawa, Y., Uchida, H., Watanabe, Y. and Sasaki, T. (1993) Chemosensitivity Testing of Advanced Lung Cancer by the Chick Embryo Assay. Annals of Cancer Research and Therapy, 2, 217-222. http://dx.doi.org/10.4993/acrt1992.2.217 
Scientific Research Publishing (SCIRP) is one of the largest Open Access journal publishers. It is currently publishing more than 200 open access, online, peer-reviewed journals covering a wide range of academic disciplines. SCIRP serves the worldwide academic communities and contributes to the progress and application of science with its publication.

Other selected journals from SCIRP are listed as below. Submit your manuscript to us via either submit@scirp.org or Online Submission Portal.
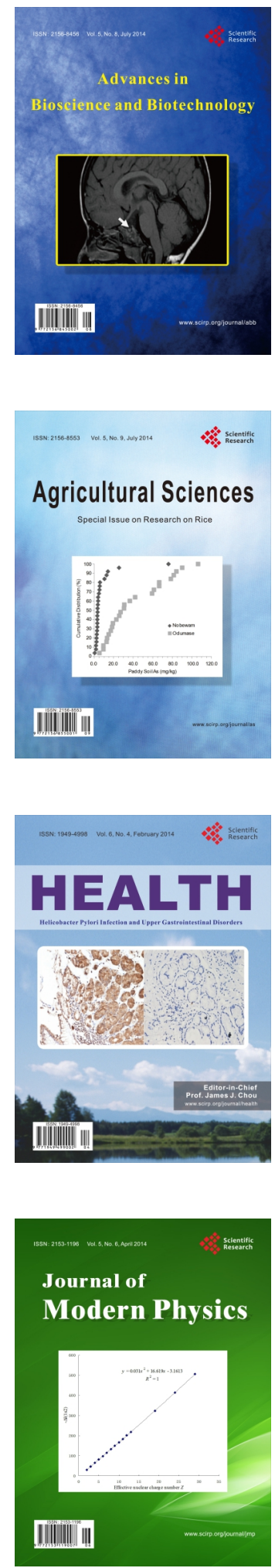
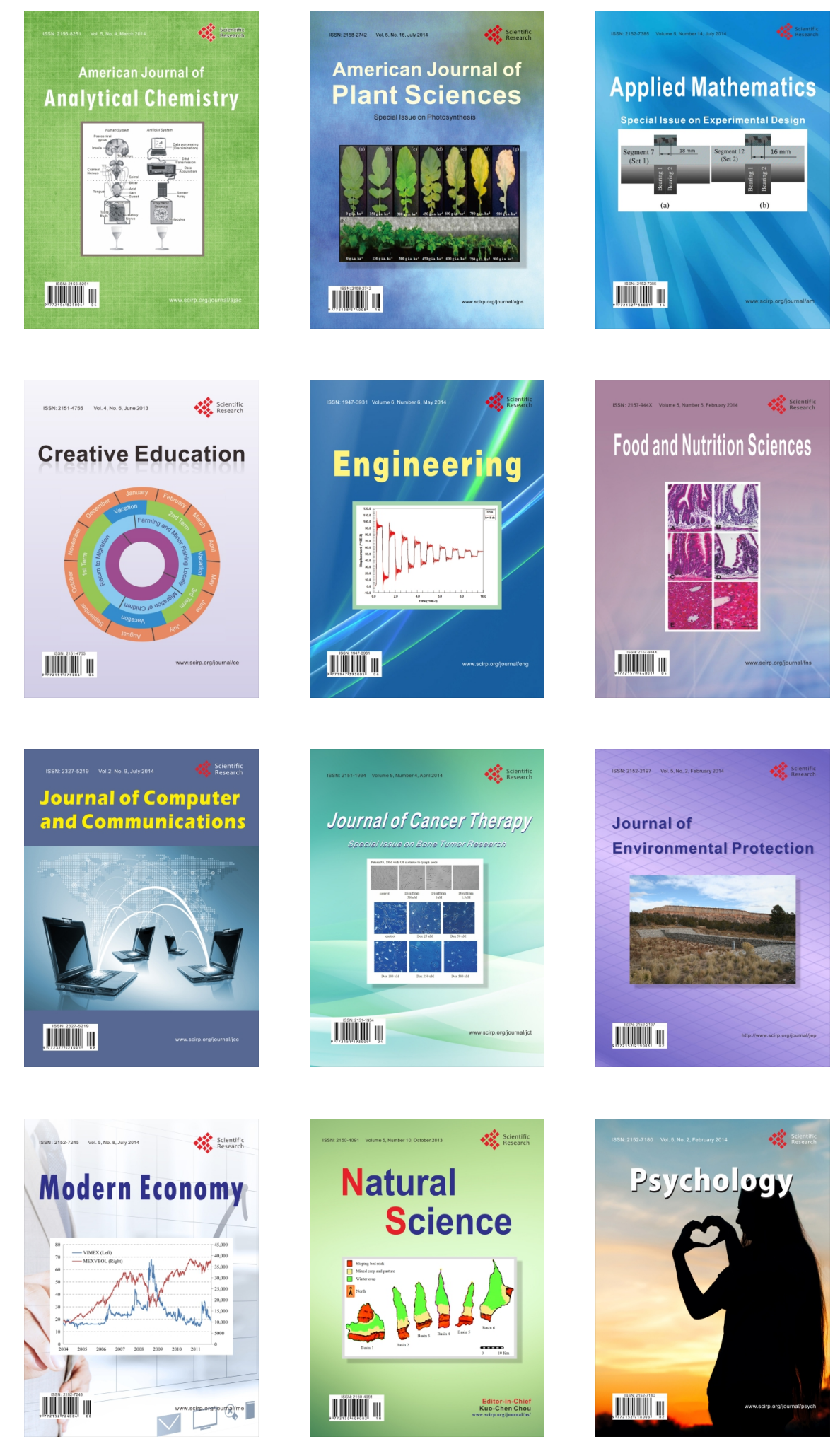